\title{
Determinants of unmet need for family planning among married women of reproductive age in Burundi: a cross-sectional study
}

Athanase Nzokirishaka ${ }^{1 *}$ and Imose Itua $^{2}$

\begin{abstract}
Background: High unmet need for family planning (32.4\%) characterized Burundi in 2010. However, there has not been any study examining the relationship between unmet need and associated factors in Burundi. The present study aims at determining the demographic, socioeconomic and other factors underlying the unmet need for contraception among married women aged 15-49 in Burundi.

Methods: This study used data from the 2010 Burundi Demographic and Health Survey. Total unmet need, unmet need for spacing and for limiting were used as outcomes and demographic, socioeconomic and other factors as independent variables. After a descriptive analysis of the study population $(n=5421)$, the association between the three outcomes and the independent variables were analysed using logistic regression. Odds ratios with their $95 \%$ confidence intervals were calculated with statistical significance at $p<0.05$.

Results: This study showed that the likelihood of total unmet need decreased with age after 35+, with an adjusted Odds Ratio $=0.586$ and $95 \% \mathrm{Cl}=0.423-0.811$, compared to women aged 15-24. Women with 4-5 and 6+ living children had higher odds [aOR $=1.850(1.322-2.590)$ and 2.390 (1.616-3.534) respectively]. Odds of unmet need were lower among women with primary [aOR $=0.741(0.618-0.888)]$ and secondary education [aOR $=0.555(0.399-0.771)]$. Women whose husband desired more children than them $[\mathrm{aOR}=1.824(1.411-2.358)]$ and those ignoring the husband's desired children [aOR $=2.700$ (2.176-3.350)] had higher odds than those desiring the same number as the husband. Women who had experienced the death of $1+$ sons had higher odds [aOR $=1.285(1.038-1.591)]$. Middle $[\mathrm{aOR}=0.670(0.530-0.846)]$ and rich $[\mathrm{aOR}=0.664(0.541-0.817)]$ compared to poor, women living in the North $[\mathrm{aOR}=0.611(0.412-0.904)]$ compared to those from Bujumbura, had lower odds. Rural women had higher odds $[\mathrm{aOR}=1.373(1.018-1.852)]$ and those who had visited a health facility $[\mathrm{aOR}=0.765(0.608-0.961)]$ or had access to TV $[\mathrm{aOR}=0.562(0.375-0.843)]$ had lower odds.
\end{abstract}

Conclusion: Tackling the unmet need for FP in Burundi requires scaling-up male involvement, promoting spousal communication, client-centred services, greater use of media, women's education, child survival, and pro-poor policies.

\footnotetext{
* Correspondence: anzokira@yahoo.fr

${ }^{1}$ Independent Consultant, Bujumbura, Burundi

Full list of author information is available at the end of the article
}

(c) The Author(s). 2018 Open Access This article is distributed under the terms of the Creative Commons Attribution 4.0 International License (http://creativecommons.org/licenses/by/4.0/), which permits unrestricted use, distribution, and reproduction in any medium, provided you give appropriate credit to the original author(s) and the source, provide a link to the Creative Commons license, and indicate if changes were made. The Creative Commons Public Domain Dedication waiver (http://creativecommons.org/publicdomain/zero/1.0/) applies to the data made available in this article, unless otherwise stated. 


\section{Background}

Unmet need for family planning designates "the number or percent of women currently married or in union who are fecund and who desire to either terminate or postpone childbearing, but who are not currently using a contraceptive method" [1].

Women with unmet need are composed of two groups: (a) Women with unmet for spacing: Those who desire to postpone their next birth by a specific length of time (for example, for at least 2 years from the date of a survey) and who do not currently use a contraceptive method.

(b) Women with unmet need for limiting: Those who desire no additional children and who do not currently use contraception.

Unmet need has been consistently used to monitor and evaluate sexual and reproductive health programmes in the framework of the Millennium Development Goals (MDGs) [2]. Compared to the contraceptive prevalence rate $(\mathrm{CPR})$, an unmet need has the advantage of introducing a rights-based approach, as it captures at the same time the woman's use of contraception and her fertility preferences.

Between 1990 and 2010, the CPR increased worldwide from 54.8 to $63.3 \%$ while unmet need decreased from 15.4 to $12.3 \%$. Still, in 2010 , the number of women with unmet need was estimated at 146 million out of which 122 million were from the developing countries, excluding China [3].

A high unmet need contributes to the perpetuation of high maternal mortality levels. Overall, while 342,203 women died of maternal causes in 2008, contraceptive use averted 272,040 (44\%), and it is estimated that meeting the current unmet need could prevent an additional $29 \%$ of maternal deaths $(104,000)$ per year worldwide [4].

Family Planning (FP) also impacts positively child survival and perinatal outcomes, through the lengthening of the inter-birth intervals. Children born within 2 years of an elder sibling have a $60 \%$ increased risk of infant death, compared with those born after 3 years or longer. Compared with inter-pregnancy intervals of 1.5 to 2 years, inter-pregnancy intervals shorter than 6 months induce an increase of $40 \%$ risks of preterm births and $60 \%$ risk of low birth weight [5].

Burundi is a small country with $27,384 \mathrm{~km}^{2}$. With a population of 8.4 million in 2010 , it was the second most densely-populated country in Africa (310 inhabitants per square $\mathrm{km}$ ). The urban population represented only $10 \%$. The population grew by $2.4 \%$ a year, and the Total Fertility Rate (TFR) remained high at 6.4 children per woman. The Government of Burundi views FP primarily as a strategy to slow down the population growth, though it does not underestimate its health benefits.
FP programmes with modern methods started in Burundi in the early 1980's and kept expanding over decades. Between 1990 and 2010, the CPR increased from 8.4 to $21.9 \%$ and unmet need increased slightly from 27 . 3 to $29.2 \%$ [3]. While unmet need decreased by $5.1 \%$ between 1990 and 2010 in developing countries, in Burundi, it increased slightly by $1.9 \%$ during the same period.

The research hypothesis of this study is that unmet need for contraception among women of childbearing age (15-49) is associated with demographic, socioeconomic as well as knowledge, practice and exposure to media factors. The aim of the study is therefore to determine those factors underlying the unmet need for contraception in Burundi.

One such factor is the woman's age. A study from Zambia [6] indicated that while unmet need increased below 34, it decreased with age, once a woman reached 34 years or more. The Zambian study also revealed that women who got married at $18+$ had a lower likelihood of unmet need.

A study from India [7] highlighted that age at first marriage was significantly associated with unwanted pregnancy yet not associated with mistimed pregnancy while another from Burkina-Faso [8] discovered that being married more than once increased the likelihood of unmet need.

The number of living children or pregnancies (some authors use the terms "ever-born children" or parity) appears as a critical predictor of unmet need in many studies [8-10].

A study on the underuse of modern methods of contraception in 35 LMICs [11] revealed that women with the lowest educational attainment were 8.6 times less likely to use contraceptives compared with the highest levels.

One study from Cameroun [12] revealed that the husband's approval of contraception and discussion about FP within the couple had a protective relationship with unmet need. A study from Rwanda [13] went on explaining that unmet need was higher among women who did not approve FP, those who believed their partner did not approve FP or who did not know his attitude and those who had never discussed FP with their partners or had done so, rarely.

Other factors found significantly associated with unmet need are low socioeconomic status, [14] the residence and region [15, 16], exposure to radio and knowledge of FP methods [17], exposure to information from health facilities [18] or counselling by a health worker [19].

In conclusion, this literature review highlighted that factors associated with unmet need vary across countries, hence the need to know which ones are at play 
and their relative importance in the context of Burundi. Such knowledge will inform the formulation and implementation of relevant policies, strategies, and interventions to tackle the unmet need in Burundi and expand contraception use.

\section{Method}

This was a cross-sectional study based on the data collected by the 2010 Burundi Demographic and Health Survey (BDHS), during the period August 2010 January 2011, under the authority of the National Statistical Office of Burundi (ISTEEBU), the National Public Health Institute (INSP) and ICF International. It was a population-based survey, aimed at updating the demographic, health and HIV-related indicators.

The 2010 BDHS used the 2008 Burundi Population and Housing Census (PHC) as the sampling frame. The sample was clustered by enumeration area (EA) and doubly stratified (by province and residence). More details are available in the BDHS final report.

All women of reproductive age found in the selected households as residents, or visitors who spent the previous night in the household, were eligible to be interviewed if they gave their informed consent. The present study was restricted to the sample of married women and those not married but living with a partner $(n=5421)$ because some of the questions in this study were related to the husband/partner's characteristics.

The data collection used face to face interviews to administer the standard questionnaire developed by the MEASURE DHS Project adapted to the Burundi context. It was a structured and pre-tested questionnaire. The DHS programme uses three types of questionnaires: the household's, the men's and the women's questionnaires. Data utilized in the present study come from the women questionnaire. The correspondent dataset file was downloaded from the DHS Measure project website and then opened directly into SPSS 21.0.

This study considered three outcomes: total unmet need, unmet need for spacing, and for limiting. The denominator for the calculation of unmet need is conventionally the total of currently married women aged 15-49 [20]. Divorced women and widows were excluded from the analysis. The numerator includes only women who were not using contraception at the time of the interview. Thus, the departing point for all calculations was a weighted sample of married women, who were first divided into those using a contraceptive method and those not using. The nonusers were first split into pregnant or amenorrhoeic women on one side, and those who were neither pregnant nor amenorrhoeic on the other. The pregnant or amenorrhoeic were then classified by whether the pregnancy or last birth was wanted at that time or unwanted. Women in the mistimed or unwanted category were considered having the unmet need for spacing and for limiting respectively. The other component of unmet need is composed of women who were neither pregnant nor amenorrhoeic. These women were further divided, into fecund and infecund. Fecund women who wanted to wait at least 2 years or who wanted no more children were regarded as having an unmet need for spacing and for limiting respectively.

Thus, the total unmet need was composed of unmet need for spacing plus the unmet need for limiting. The absolute number of women with unmet and met needs constitute the total demand for FP. The proportion of satisfied demand equals the percentage of the met need by the demand [1].

Independent variables were derived from the literature review and the 2010 BDHS questionnaire. They were mostly categorical and the few continuous, for example age, were categorized.

The wealth index was constructed by DHS program based on dwelling and household characteristics and assets. In this study, the five categories or quintiles of the wealth index (poorest, poorer, middle, richer, richest) were collapsed into three: poor regroups the bottom two quintiles and rich the top two quintiles. Middle remains unchanged.

A descriptive analysis examined the distribution of the sample of married women per demographic and socioeconomic characteristics as well as per their knowledge, practices, and exposure to media. Chisquared tests with $p<0.05$ were conducted to determine whether there was an association between an independent variable and an outcome. The univariate analysis allowed to assess the likelihood of total unmet need, unmet need for spacing and unmet need for limiting among women with certain characteristics using logistic regression to calculate unadjusted odds ratios with their $95 \%$ CI. A multivariate analysis, using logistic regression, examined the independent effect of each factor after controlling for confounders. Statistical significance was claimed if $\mathrm{p}$ was $<0.05$ and CI did not span the unity. All $p$-values presented were based on two-tailed hypothesis.

The multivariate analysis was carried out on an unweighted sample of 3016 women who had an unmet need for spacing $(n=1701)$ or for limiting $(n=1315)$. Women who wanted another child in 2 years and infecund or menopausal were excluded from the analysis as they did not have an unmet need. An unweighted sample was used to respect the principle of matching a response with an individual. Adjusted Odds Ratios (aOR) with their 95\% CI were estimated using two models: 
- A multinomial logistic regression to analyze the unmet need for spacing (coded as 1) and the unmet need for limiting (coded as 2). The other category of women in the sample, coded as "met need" (coded 0), was considered as the reference category. A multinomial regression was appropriate as the outcome had more than two categories.

- A binary logistic regression to analyze the total demand for FP dichotomized into an unmet need (coded as 1) and met need (coded as 0 ) as a reference category.

\section{Results}

\section{Differentials of unmet need}

Results of descriptive analysis (Table 1) show that $64 \%$ of married women were aged below 35 years while $72.5 \%$ were aged 18 years and above when they got married or started cohabitating. Nine women (88. $1 \%)$ out of ten had been married more than once and eight women out of ten (80.6\%) had less than six living children.

93.7\% of respondents had primary education or no education at all, while $90.7 \%$ of women had husbands with primary or no education at all. Nine out of ten households $(88.7 \%)$ were headed by males. $61.1 \%$ of participants were of the Catholic religion and $31.3 \%$ were Protestants. The ideal number of children for the majority of women (52.4\%) was $4-5$. While $43.4 \%$ of women desired the same number of children as their husbands, almost three women out of ten (28.1\%) ignored their husband's fertility preferences.

More than three-quarters of respondents $(78.2 \%)$ had not experienced the death of a daughter and $76.3 \%$ had not experienced the death of a son. $61.2 \%$ of women belonged to the poor and middle categories of the wealth index, $85 \%$ were self-employed and $81.7 \%$ were working at the time of the interview. Participants were largely rural (91.5\%) and concentrated in the North (30\%) and the Central-East (25.8\%).

A large majority (94.9\%) had not been visited by an FP worker during the last 12 months preceding the interview. In contrast, $79.1 \%$ had visited a health facility during the same period. Practically, all women (99.2\%) knew at least a modern contraception method while following proportions of women had not heard FP messages from newspapers/magazines (98\%), radio (54.7\%) and TV (97.1\%).

\section{Prevalence of unmet need}

Table 2 summarizes the distribution of the weighted sample of 5421 married women into six main groups: women with unmet need for spacing and for limiting, women with a met need for spacing and for limiting and women with no unmet need and infecund/menopausal women. Women with "met need" should not be confused with women with "no unmet need". The former group refers to women using contraception, the latter to non-users. Among non-users, pregnant or amenorrhoeic women whose pregnancy or last child were wanted are considered as with "no unmet need". So are not pregnant nor amenorrhoeic women wanting their next child within 2 years [16].

Unmet need among married women in Burundi stood at $32.4 \%$ (22.6\% for spacing and $9.8 \%$ for limiting), against a met need of $21.9 \%$ (13.6\% for spacing and 8 . $3 \%$ for limiting) in 2010. Thus, the total demand for FP (unmet need plus met need) was $54.3 \%$. The proportion of satisfied demand was only $40.3 \%$ (37.6\% for spacing and $45.9 \%$ for limiting).

\section{Bivariate analysis}

The bivariate analysis provided a preliminary look at the characteristics of women with total unmet need, unmet need for spacing and for limiting, using a Pearson's chi-squared test with a $p$-value $<0.05$. Variables with $p<0.05$ were selected to be included in the multivariate analysis (Tables 3, 4 and 5).

\section{Multivariate logistic regression results}

Table 3 shows that unmet need for spacing is significantly associated with women aged $15-24$ [aOR $=3.048$ (2.114-4.393] and 25-34 [aOR $=2.436$ (1.850-3.207)] compared to women aged $35+$. Women whose ideal number of children was between zero and three $[\mathrm{aOR}=0.443$ (0.330-0.595)] or four and five [aOR $=0.696(0.534-0.907)$ were more protected against the unmet need for spacing than those whose ideal number of children was six and more.

Women with no education [aOR $=1.511(1.006-2.270)]$ were more exposed to the unmet need for spacing than those with secondary and above education.

The likelihood of the unmet need for spacing was lower when both spouses desired the same number of children $[\mathrm{aOR}=0.385(0.303-0.488)]$, when the husband wanted more children than the wife $[\mathrm{aOR}=0.704$ (0.509-0.975)] or fewer children [aOR $=0.450(0.335-0.604)]$, compared to when the woman ignored the number of children her husband desired.

In terms of economic factors, poor women $[\mathrm{aOR}=1.453$ (1.148-1.839)] had higher odds of unmet need for spacing than rich. Urban women $[\mathrm{aOR}=0.703(0.501-0.987)] \mathrm{com}$ pared to rural, women living in the Northern Region $[\mathrm{aOR}=0.585(0.375-0.913)]$ compared to those from Bujumbura had lower odds of unmet need for spacing.

Lastly, women who did not have access to FP messages through radio or TV were more exposed to unmet need for spacing with $[\mathrm{aOR}=1.228(1.022-1.477)]$ and $[\mathrm{aOR}=1.635(1.017-2.629)]$ respectively. 
Table 1 Demographic, socioeconomic and other characteristics of married women aged 15-49 years in Burundi, 2010

\begin{tabular}{lll}
\hline Characteristics $(n=5421)$ & Number & Percent \\
\hline Woman's age & & \\
$15-24$ & 1307 & 24.1 \\
$25-34$ & 2161 & 39.9 \\
$35+$ & 1954 & 36.0 \\
Age at first cohabitation & & \\
$<18$ & 1490 & 27.5 \\
$>18$ & 3931 & 72.5
\end{tabular}

Number of unions

More than once

Once

Number of living children

$0-1$

$2-3$

$4-5$

$6+$

Woman's education

No education

Primary

Secondary +

Husband/partner's education

No education

Primary

Secondary+

Don't know

Sex of head of household

Male

Female

Religion

Catholic
Protestant

deal number of children

0-3

4-5

6+

Husband's desire for children

Both same

Husband wants more

Husband wants fewer

Don't know

Daughters dead

$$
0
$$

$1+$

Sons dead

0

$1+$
5523

744

1045

1935

1386

1055

2931

2145

344

2345

2571

448

57

4809

611

88.1

11.9

19.3

35.7

25.6

19.4

54.1

39.6

6.3

43.3

47.4

8.3

1.0

88.7

11.3

3314

1696

412

1552

2841

1028

2334

715

818

1510

4239

1183

4135

1285
Table 1 Demographic, socioeconomic and other characteristics of married women aged 15-49 years in Burundi, 2010 (Continued)

\begin{tabular}{lll}
\hline Characteristics $(n=5421)$ & Number & Percent \\
\hline Wealth index & 2189 & 40.4 \\
Poor & 1129 & 20.8 \\
Middle & 2102 & 38.8 \\
$\quad$ Rich & & \\
Respondent works for & 242 & 4.9 \\
$\quad$ Family member & 499 & 10.1 \\
Someone else & 4183 & 85.0 \\
Self-employed & &
\end{tabular}

Respondent worked in last 12 months

$\begin{array}{lll}\text { No } & 497 & 9.2 \\ \text { In the past year } & 493 & 9.1 \\ \text { Currently working } & 3980 & 73.4 \\ \text { Have a job but on leave last 7 days } & 450 & 8.3\end{array}$

Respondent currently working

$\begin{array}{lll}\text { No } & 991 & 18.3 \\ \text { Yes } & 4430 & 81.7\end{array}$

Place of residence

$\begin{array}{lll}\text { Urban } & 460 & 8.5 \\ \text { Rural } & 4961 & 91.5\end{array}$

Region

$\begin{array}{lll}\text { Bujumbura } & 294 & 5.4\end{array}$

$\begin{array}{lll}\text { North } & 1625 & 30.0\end{array}$

$\begin{array}{lll}\text { Central-East } & 1397 & 25.8\end{array}$

West $\quad 993 \quad 18.3$

$\begin{array}{lll}\text { South } & 1110 & 20.5\end{array}$

Visited by an FP worker

No $\quad 5145$

94.9

Yes

277

5.1

Visited a health facility

$\begin{array}{lll}\text { No } & 1133 & 20.9 \\ \text { Yes } & 4288 & 79.1\end{array}$

Knowledge of any method

Knows no modern method

43

0.8

Knows any modern method

Heard FP in newspapers/magazine

5377

98.0

Yes

5309

2.0

Heard FP on radio

No

2962

54.7

Yes

45.3

Heard FP on TV

\begin{tabular}{lll} 
No & 5260 & 97.1 \\
Yes & 156 & 2.9 \\
\hline
\end{tabular}


Table 2 Distribution of married women according to main categories of unmet need

\begin{tabular}{lll}
\hline & Percent & Number of women \\
\hline Unmet need for spacing & 22.6 & $(1225)$ \\
Unmet need for limiting & 9.8 & $(531)$ \\
Met need for spacing & 13.6 & $(735)$ \\
Met need for limiting & 8.3 & $(451)$ \\
No unmet need & 35.0 & $(1898)$ \\
Infecund, menopausal & 10.7 & $(579)$ \\
Sub-total & 100.0 & $(5419)$ \\
Missing & 0.0 & 2 \\
Total & 100.0 & $(5421)$ \\
\hline
\end{tabular}

Results of the multivariate regression analysis (Table 4) show that unmet need for limiting was associated with old women aged 35+. Women aged 15-24 and 25-34 were less likely to experience it compared to those aged $35+$ with respectively $[\mathrm{aOR}=0.230(0.097-0.547)]$ and [aOR $=0.551(0.398-0.762)]$. Women whose ideal number of children was zero to three $[\mathrm{aOR}=1.793(1.218-2.639)]$ were more likely to experience it, compared to those desiring six children and above. Similarly, the number of living children was found a key predictor of unmet need for limiting with respectively $[\mathrm{aOR}=0.017(0.002-0.132)$ ), $[\mathrm{aOR}=0.172(0.112-0.266)]$ and $[\mathrm{aOR}=0.521 \quad(0.385-0$. 705)] for women with zero to one child, two to three and four to five children, compared to women with $6+$ living children.

Women desiring the same number of children as the husband $[\mathrm{aOR}=0.481(0.352-0.659)]$ and those whose husband wanted fewer children $[\mathrm{aOR}=0.452(0.305-0$. 671)] were more protected against the unmet need for limiting than those who ignored their husband's fertility preferences. This analysis also found a protective association between unmet need for limiting and having no experience of a girl death $[\mathrm{aOR}=0.729(0.548-0.970)]$ or a boy death $[\mathrm{aOR}=0.748(0.566-0.989)]$. Poor women compared to rich $[\mathrm{aOR}=1.382(1.013-1.884)]$, women who had not visited a health facility during the last 12 months preceding the survey $[\mathrm{aOR}=1.586(1.166-2.156)]$ were found significantly associated with unmet need for limiting.

The number of unions, woman's education, husband's education, place of residence, region, exposure to radio or TV, which were univariately associated with unmet need for limiting lost significance in the multivariate analysis. Religion showed no association with unmet need for limiting neither in univariate nor in multivariate analysis.

Results of the multivariate logistic regression concerning total unmet need (Table 5) show that the likelihood of total unmet need decreased with the woman's age, but the difference became significant after the woman was 35 years old, compared to women in the age group $15-24[\mathrm{aOR}=0.586,(0.423-0.811)]$. On the other hand, four to five and 6+ living children were found significantly associated with total unmet need with respectively $[\mathrm{aOR}=1.850(1.322-2.590)]$ and $[\mathrm{aOR}=2.390(1.616-3.534)]$. The association between the number of unions and the husband/partner's education with total unmet need found by the univariate model was lost in the multivariate model.

The multivariate model also revealed that total unmet need had a protective association with women educated at primary $[\mathrm{aOR}=0.741(0.618-0.888)]$ and secondary + [a OR = 0.555 (0.399-0.771) ] levels. The husband/partner's education which showed an association with total unmet need in the univariate analysis lost significance in the multivariate analysis. In contrast, the husband's desire for children emerged as significantly associated with total unmet need both in univariate and multivariate models. The likelihood for total unmet need was higher among women whose husbands wanted more children $(\mathrm{aOR}=1.824$ (1.411-2.358)] or did not know the number of children desired by their husbands $[\mathrm{aOR}=2.700(2.176-3.350)]$, relative to women desiring the same number of children as the husband. The total unmet need was also found associated with women who had already experienced the death of a son or more, compared to those who had not $[\mathrm{aOR}=1.285(1.038-1.591)]$.

In the adjusted model, middle $[\mathrm{aOR}=0.670(0.530-0.846)]$ and rich $[\mathrm{aOR}=0.664(0.541-0.817)]$ categories of the wealth index had lower odds of total unmet need than the poor. Rural women compared to urban $[\mathrm{aOR}=1.373$ (1.018-1.852)] and women from the Northern Region compared to those from Bujumbura $[\mathrm{aOR}=0.611(0.412-0.904)]$ had higher and lower odds of total unmet need respectively. Lastly, the model detected that odds of the total unmet need for women who had visited a health facility during the last 12 months preceding the survey $[\mathrm{aOR}=0.765(0.608-0.961)]$ and those who had accessed TV messages $[\mathrm{aOR}=0.562(0.375-0.843)]$ were reduced.

\section{Discussion}

This report highlighted that unmet need was higher for spacing $(22.6 \%)$ than for limiting $(9.8 \%)$, with a total of $32.4 \%$. These estimates are consistent with those found in other reports: Using the revised definition of unmet need, another study [20] also estimated the total unmet need for Burundi at $32.4 \%$. A third study [3], using a Bayesian hierarchical model combined with countryspecific time trends to estimate the total unmet need of LMICs estimated the total unmet need for Burundi at 29.2\% (95\%CI: 20.0-39.7\%). Lastly, the final 2010 BDHS report estimated the total unmet need at $31 \%$ (i.e. $21.5 \%$ for spacing and $9.5 \%$ for limiting). The difference with the present report is attributable to the fact that in the BDHS final report, non-users, pregnant or amenorrhoeic 
Table 3 Likelihood estimates of unmet need for spacing among married women aged 15-49 years in Burundi, 2010 (logistic regression analysis), $n=3016$

\begin{tabular}{|c|c|c|c|c|}
\hline Variables & OR $(95 \% \mathrm{Cl})$ & $p$-value & Adjusted OR (95\% Cl) & $p$-value \\
\hline \multicolumn{5}{|l|}{ Woman's age } \\
\hline $15-24$ & $2.115(1.690-2.647)$ & 0.000 & $3.048(2.114-4.393)$ & 0.000 \\
\hline $25-34$ & $2.043(1.674-2.492)$ & 0.000 & $2.436(1.850-3.207)$ & 0.000 \\
\hline $35+$ (reference) & 1 & & 1 & \\
\hline \multicolumn{5}{|l|}{ Number of unions } \\
\hline Once & $0.922(0.684-1.244)$ & & $0.971(0.690-1.366)$ & 0.866 \\
\hline More than once (reference) & 1 & & 1 & \\
\hline \multicolumn{5}{|l|}{ Ideal number of children } \\
\hline $0-3$ & $0.290(0.225-0.374)$ & 0.000 & $0.443(0.330-0.595)$ & 0.000 \\
\hline $4-5$ & $0.531(0.423-0.667)$ & 0.000 & $0.696(0.534-0.907)$ & 0.007 \\
\hline $6+$ (reference) & 1 & & 1 & \\
\hline \multicolumn{5}{|l|}{ Number of living children } \\
\hline $0-1$ & $1.130(0.845-1.511)$ & 0.408 & $0.935(0.606-1.443)$ & 0.762 \\
\hline $2-3$ & $1.550(1.212-1.982)$ & 0.000 & 1.107 (0.786-1.560) & 0.560 \\
\hline $4-5$ & 1.490 (1.149-1.932) & 0.003 & $1.270(0.931-1.732)$ & 0.131 \\
\hline $6+$ (reference) & 1 & & 1 & \\
\hline \multicolumn{5}{|l|}{ Woman's education } \\
\hline No education & $3.848(2.938-5.038)$ & 0.000 & $1.511(1.006-2.270)$ & 0.047 \\
\hline Primary & $2.863(2.187-3.748)$ & 0.000 & $1.261(0.862-1.846)$ & 0.232 \\
\hline Secondary+ (reference) & 1 & & 1 & \\
\hline \multicolumn{5}{|l|}{ Religion } \\
\hline Catholic & $1.282(0.971-1.691)$ & 0.079 & $1.060(0.764-1.469)$ & 0.728 \\
\hline Protestant & $1.643(1.227-2.202)$ & 0.001 & $1.188(0.844-1.672)$ & 0.323 \\
\hline Muslim, others (reference) & 1 & & 1 & \\
\hline \multicolumn{5}{|l|}{ Husband/partner's education } \\
\hline No education & $5.187(3.009-8.941)$ & 0.000 & $0.792(0.341-1.836)$ & 0.586 \\
\hline Primary & $4.251(2.479-7.290)$ & 0.000 & $0.696(0.303-1.600)$ & 0.394 \\
\hline Secondary+ & $1.791(1.010-3.178)$ & 0.046 & $0.681(0.283-1.637)$ & 0.391 \\
\hline Don't know (reference) & 1 & & 1 & \\
\hline \multicolumn{5}{|l|}{ Husband's desire for children } \\
\hline Both same & $0.297(0.239-0.369)$ & 0.000 & $0.385(0.303-0.488)$ & 0.000 \\
\hline Husband wants more & $0.570(0.423-0.769)$ & 0.000 & $0.704(0.509-0.975)$ & 0.035 \\
\hline Husband wants fewer & $0.342(0.260-0.450)$ & 0.000 & $0.450(0.335-0.604)$ & 0.000 \\
\hline Don't know (reference) & 1 & & 1 & \\
\hline \multicolumn{5}{|l|}{ Daughters dead } \\
\hline 0 & $0.864(0.698-1.070)$ & 0.182 & $0.841(0.653-1.084)$ & 0.182 \\
\hline $1+$ (reference) & 1 & & 1 & \\
\hline \multicolumn{5}{|l|}{ Sons dead } \\
\hline 0 & $0.863(0.700-1.063)$ & 0.167 & $0.845(0.662-1.080)$ & 0.179 \\
\hline $1+$ (reference) & 1 & & 1 & \\
\hline
\end{tabular}


Table 3 Likelihood estimates of unmet need for spacing among married women aged 15-49 years in Burundi, 2010 (logistic regression analysis), $n=3016$ (Continued)

\begin{tabular}{|c|c|c|c|c|}
\hline Variables & OR $(95 \% \mathrm{Cl})$ & $p$-value & Adjusted OR (95\% Cl) & $p$-value \\
\hline \multicolumn{5}{|l|}{ Wealth index } \\
\hline Poor & $2.351(1.963-2.817)$ & 0.000 & $1.453(1.148-1.839)$ & 0.002 \\
\hline Middle & $1.662(1.333-2.071)$ & 0.000 & 1.070 (0.820-1.396) & 0.617 \\
\hline Rich (reference) & 1 & & 1 & \\
\hline \multicolumn{5}{|l|}{ Place of residence } \\
\hline Urban & $0.356(0.291-0.434)$ & 0.000 & $0.703(0.501-0.987)$ & 0.042 \\
\hline Rural (reference) & 1 & & 1 & \\
\hline \multicolumn{5}{|l|}{ Region } \\
\hline South & $3.393(2.509-4.588)$ & 0.000 & 1.139 (0.733-1.770) & 0.563 \\
\hline North & $1.613(1.208-2.154)$ & 0.001 & $0.585(0.375-0.913)$ & 0.018 \\
\hline Centre-East & $2.685(2.020-3.569)$ & 0.000 & $0.859(0.552-1.338)$ & 0.502 \\
\hline West & $4.226(3.091-5.778)$ & 0.000 & $1.321(0.837-2.082)$ & 0.231 \\
\hline Bujumbura (reference) & 1 & & 1 & \\
\hline \multicolumn{5}{|l|}{ Visited by a FP worker } \\
\hline No & $1.605(1.100-2.343)$ & 0.014 & $1.340(0.879-2.042)$ & 0.174 \\
\hline Yes (reference) & 1 & & 1 & \\
\hline \multicolumn{5}{|l|}{ Visited a health facility } \\
\hline No & $1.143(0.923-1.415)$ & 0.001 & 1.199 (0.928-1.548) & 0.165 \\
\hline Yes (reference) & 1 & & 1 & \\
\hline \multicolumn{5}{|l|}{ Heard FP messages on radio } \\
\hline No & $1.737(1.481-2.037)$ & 0.000 & $1.228(1.022-1.477)$ & 0.029 \\
\hline Yes (reference) & 1 & & 1 & \\
\hline \multicolumn{5}{|l|}{ Heard FP messages on TV } \\
\hline No & $4.660(3.207-6.772)$ & & $1.635(1.017-2.629)$ & 0.043 \\
\hline Yes (reference) & 1 & & 1 & \\
\hline
\end{tabular}

women and those whose pregnancy was due to a contraception failure were not included in the category of unmet need.

The multivariate analysis confirmed that other factors being constant, unmet need for spacing was significantly associated with young women between 15 and 34 and unmet need for limiting with older women aged $35+$. The total unmet need was associated with women aged $35+$ compared to women aged 15-24.

The husband's desire for children has emerged as a dominant factor shaping unmet need for spacing, for limiting and total unmet need. Unmet need for spacing was less likely when both spouses wanted the same number of children, or the husband wanted more or fewer children compared to women ignoring their husband's fertility intentions. The husband's desire for children affected significantly unmet need for limiting when the two spouses wanted the same number of children or the husband wanted fewer children. It affected the total unmet need the same way. The ignorance of the husband's desire for children can be an indication of lack of spousal communication on fertility and FP.

The sexual and reproductive health programme (SRHP) should involve males in all programming stages so that they can support their wife in using FP and inter-spousal dialogue on fertility and FP can be promoted [21].

The ideal number of children is another powerful factor underlying the unmet need for spacing and for limiting. The unmet need for spacing increases with the ideal number of children, meaning that the more children the women desire, the more they want to space them. On the other hand, unmet need for limiting was associated with women wanting a small family of zero to three children. These women seem to prefer to cease childbearing soon after their fertility goal is achieved. Further studies should confirm the likelihood of the unmet need for limiting among women desiring zero to three children as there is a possibility of a response bias. A maximum of 
Table 4 Likelihood estimates of unmet need for limiting among married women aged 15-49 years in Burundi, 2010 (logistic regression analysis), $n=3016$

\begin{tabular}{|c|c|c|c|c|}
\hline Variables & OR $(95 \% \mathrm{Cl})$ & $p$-value & Adjusted OR (95\% Cl) & $p$-value \\
\hline \multicolumn{5}{|l|}{ Woman's age } \\
\hline $15-24$ & $0.037(0.020-0.069)$ & 0.000 & $0.230(0.097-0.547)$ & 0.001 \\
\hline $25-34$ & $0.215(0.169-0.273)$ & 0.000 & $0.551(0.398-0.762)$ & 0.000 \\
\hline $35+$ (reference) & 1 & & & \\
\hline \multicolumn{5}{|l|}{ Number of unions } \\
\hline Once & $0.542(0.389-0.754)$ & 0.000 & $0.830(0.555-1.241)$ & 0.364 \\
\hline More than once (reference) & 1 & & 1 & \\
\hline \multicolumn{5}{|l|}{ Ideal number of children } \\
\hline $0-3$ & $0.953(0.689-1.317)$ & 0.769 & $1.793(1.218-2.639)$ & 0.003 \\
\hline $4-5$ & $0.726(0.529-0.997)$ & 0.048 & $1.283(0.888-1.853)$ & 0.185 \\
\hline $6+$ (reference) & 1 & & 1 & \\
\hline \multicolumn{5}{|l|}{ Number of living children } \\
\hline $0-1$ & $0.012(0.005-0.034)$ & 0.000 & $0.017(0.002-0.132)$ & 0.000 \\
\hline $2-3$ & $0.085(0.062-0.118)$ & 0.000 & $0.172(0.112-0.266)$ & 0.000 \\
\hline $4-5$ & $0.361(0.281-0.464)$ & 0.000 & $0.521(0.385-0.705)$ & 0.000 \\
\hline $6+$ (reference) & 1 & & 1 & \\
\hline \multicolumn{5}{|l|}{ Woman's education } \\
\hline No education & $6.757(4.525-10.091)$ & 0.000 & $1.696(0.906-3.172)$ & 0.098 \\
\hline Primary & $2.612(1.723-3.960)$ & 0.000 & 1.035 (0.566-1.894) & 0.910 \\
\hline Secondary+ (reference) & 1 & & 1 & \\
\hline \multicolumn{5}{|l|}{ Religion } \\
\hline Catholic & $1.202(0.858-1.683)$ & 0.284 & $0.996(0.648-1.530)$ & 0.985 \\
\hline Protestant & $0.969(0.671-1.401)$ & 0.868 & $0.827(0.520-1.314)$ & 0.421 \\
\hline Muslim, others (reference) & 1 & & 1 & \\
\hline \multicolumn{5}{|l|}{ Husband/partner's education } \\
\hline No education & $3.926(2.173-7.094)$ & 0.000 & $0.599(0.172-2.085)$ & 0.420 \\
\hline Primary & $1.744(0.964-3.157)$ & 0.066 & $0.544(0.157-1.889)$ & 0.338 \\
\hline Secondary+ & $0.854(0.442-1.648)$ & 0.638 & $0.508(0.138-1.869)$ & 0.308 \\
\hline Don't know (reference) & 1 & & 1 & \\
\hline \multicolumn{5}{|l|}{ Husband's desire for children } \\
\hline Both same & $0.333(0.254-0.437)$ & 0.000 & $0.481(0.352-0.659)$ & 0.000 \\
\hline Husband wants more & $0.780(0.546-1.113)$ & 0.170 & $0.845(0.559-1.276)$ & 0.423 \\
\hline Husband wants fewer & $0.379(0.268-0.537)$ & 0.000 & $0.452(0.305-0.671)$ & 0.000 \\
\hline Don't know (reference) & 1 & & 1 & \\
\hline \multicolumn{5}{|l|}{ Daughters dead } \\
\hline 0 & $0.355(0.281-0.448)$ & 0.000 & $0.729(0.548-0.970)$ & 0.030 \\
\hline $1+$ (reference) & 1 & & 1 & \\
\hline \multicolumn{5}{|l|}{ Sons dead } \\
\hline 0 & $0.321(0.255-0.403)$ & 0.000 & $0.748(0.566-0.989)$ & 0.042 \\
\hline $1+$ & 1 & & 1 & \\
\hline
\end{tabular}


Table 4 Likelihood estimates of unmet need for limiting among married women aged 15-49 years in Burundi, 2010 (logistic regression analysis), $n=3016$ (Continued)

\begin{tabular}{|c|c|c|c|c|}
\hline Variables & OR (95\% Cl) & $p$-value & Adjusted OR (95\% Cl) & $p$-value \\
\hline \multicolumn{5}{|l|}{ Wealth index } \\
\hline Poor & $2.387(1.906-2.990)$ & 0.000 & $1.382(1.013-1.884)$ & 0.041 \\
\hline Middle & $1.420(1.063-1.896)$ & 0.018 & $0.725(0.502-1.048)$ & 0.087 \\
\hline Rich (reference) & 1 & & 1 & \\
\hline \multicolumn{5}{|l|}{ Place of residence } \\
\hline Urban & $0.345(0.264-0.452)$ & 0.000 & $0.865(0.550-1.361)$ & 0.531 \\
\hline Rural (reference) & 1 & & & \\
\hline \multicolumn{5}{|l|}{ Region } \\
\hline South & $4.146(2.653-6.482)$ & 0.000 & $1.127(0.596-2.132)$ & 0.713 \\
\hline North & $2.536(1.649-3.902)$ & 0.000 & $0.776(0.408-1.477)$ & 0.440 \\
\hline Centre-East & $4.293(2.815-6.546)$ & 0.000 & $1.192(0.631-2.251)$ & 0.589 \\
\hline West & $5.825(3.711-9.142)$ & 0.000 & $1.459(0.756-2.816)$ & 0.260 \\
\hline Bujumbura (reference) & 1 & & 1 & \\
\hline \multicolumn{5}{|l|}{ Visited by a FP worker } \\
\hline No & $1.029(0.670-1.580)$ & 0.895 & $1.185(0.704-1.995)$ & 0.523 \\
\hline Yes (reference) & 1 & & 1 & \\
\hline \multicolumn{5}{|l|}{ Visited a health facility } \\
\hline No & $1.742(1.359-2.233)$ & 0.000 & $1.586(1.166-2.156)$ & 0.003 \\
\hline Yes (reference) & 1 & & 1 & \\
\hline \multicolumn{5}{|c|}{ Heard FP messages on radio } \\
\hline No & $1.340(1.096-1.639)$ & 0.004 & $0.993(0.772-1.277)$ & 0.957 \\
\hline Yes (reference) & 1 & & & \\
\hline \multicolumn{5}{|l|}{ Heard FP messages on TV } \\
\hline No & $5.032(2.937-8.622)$ & 0.000 & $1.787(0.883-3.616)$ & 0.106 \\
\hline Yes (reference) & 1 & & 1 & \\
\hline
\end{tabular}

three children per family being the norm in the official discourse, some women could have responded to the question about the ideal number of children by what is considered "politically correct".

The multivariate analysis found out that the number of living children was significantly and positively associated with both unmet needs for limiting and total but not with the unmet need for spacing. The apparent association between the number of living children and unmet need for spacing, in the univariate analysis, was eliminated in the multivariate analysis, which means that the association in univariate analysis was due to confounders such as the ideal number of children. The association between unmet need and parity was found in many other studies. In Ethiopia, the number of living children was one of the factors affecting the unmet need for limiting [20] while in Uganda, it affected both the spacing, limiting and the total unmet need [22].

The multivariate analysis revealed the existence of a protective association between education and total unmet need and a positive association between women with no education and unmet need for spacing while no association was found between unmet need for limiting and woman's education. These associations lost strength though, moving from the univariate to the multivariate analysis. The multivariate analysis showed that these findings were largely due to confounding. In Ethiopia [18], women with lower education were more likely to have both unmet needs for spacing and for limiting and in Nigeria [8] women with primary and secondary education were more likely to have an unmet need for spacing. These results point to the need to take the context into account when examining those associations.

The experience of the loss of a girl child was found significantly associated with unmet need for limiting and that of a son with both unmet needs for limiting and total unmet need. The death of a child, therefore, acted as a deterrent to the use of contraception for limiting. Women who lost a child tended to resume reproduction as soon as possible, to replace the loss. To be successful 
Table 5 Likelihood estimates of total unmet need among married women aged 15-49 years in Burundi, 2010 (logistic regression analysis), $n=3016$

\begin{tabular}{lllll}
\hline Variables & OR $(95 \% \mathrm{Cl})$ & $p$-value & Adjusted OR $(95 \% \mathrm{Cl})$ & \\
\hline Woman's age & & & & \\
$15-24$ (reference) & 1 & & 1 & $0.800(0.626-1.023)$ \\
$25-34$ & $1.119(0.927-1.350)$ & 0.243 & $0.586(0.423-0.811)$ & 0.074 \\
$35+$ & $1.309(1.076-1.593)$ & 0.007 & 0.001
\end{tabular}

Age at first cohabitation

$<18$ (reference) 1

$\geq 18$

$0.866(0.734-1.023)$

0.090

Number of unions

Once (reference)

More than once

$1.313(1.006-1.714)$

0.045

Number of living children

0-1 (reference)

2-3

$1.497(1.1901 .833)$

0.001

$1.953(1.540-2.477)$

0.000

$6+$

$2.705(2.096-3.491)$

0.000

Woman' education

No education (reference)

1

Primary

Secondary+

$0.609(0.520-0.713)$

0.000

0.000

$0.218(0.171-0.277)$

Husband/partner's education

No education (reference)

Primary

Secondary+

Don't know

$0.675(0.574-0.795)$

0.000

$0.296(0.234-0.375)$

0.000

$0.217(0.140-0.335)$

0.000

Husband's desire for children

Both same (reference)

Number of dead sons

Wealth index

Place of residence

Region
Husband wants more

Husband wants fewer

Don't know

0 (reference)

$1+$

Poor (reference)

Middle

Rich

Urban (reference)

Rural

$0.352(0.295-0.421)$

Bujumbura (reference)

North

Centre-East

$2.049(1.606-2.614)$

$1.147(0.926-1.422)$

$3.256(2.651-4.000)$

$1.670(1.389-2.006)$

$0.670(0.541-0.831)$

$0.423(0.359-0.499)$

West
$1.840(1.418-2.388)$

3.080 (2.379-3.989)

4.619 (3.465-6.159)

1

0.000

0.000

0.000
$0.741(0.618-0.888)$

0.001

$1.311(0.986-1.743)$

0.062

$1.850(1.322-2.590)$

0.000

$2.390(1.616-3.534)$

0.000

$0.555(0.399-0.771)$

0.000
0.000

0.210

0.000

0.000

0.000

0.000

0.000

$.373(1.018-1.852)$

$0.611(0.412-0.904)$

$0.930(0.629-1.375)$

$1.406(0.933-2.119)$
0.000

0.375

0.000

0.021

0.001

0.000

0.038

0.014

0.715

0.104 
Table 5 Likelihood estimates of total unmet need among married women aged 15-49 years in Burundi, 2010 (logistic regression analysis), $n=3016$ (Continued)

\begin{tabular}{|c|c|c|c|c|}
\hline Variables & OR $(95 \% \mathrm{Cl})$ & $p$-value & Adjusted OR (95\% Cl) & $p$-value \\
\hline South & $3.578(2.713-4.719)$ & 0.000 & $1.161(0.783-1.720)$ & 0.457 \\
\hline \multicolumn{5}{|c|}{ Visited a health facility last 12 months } \\
\hline No (reference) & 1 & & 1 & \\
\hline Yes & $0.757(0.625-0.917)$ & & $0.765(0.608-0.961)$ & 0.022 \\
\hline \multicolumn{5}{|c|}{ Heard FP in newspapers/magazine } \\
\hline No (reference) & 1 & & & \\
\hline Yes & $0.301(0.196-0.463)$ & 0.000 & & \\
\hline \multicolumn{5}{|l|}{ Heard FP on TV } \\
\hline No (reference) & 1 & & & \\
\hline Yes & $0.210(0.151-0.290)$ & 0.000 & $0.562(0.375-0.843)$ & 0.005 \\
\hline
\end{tabular}

thus, SRH programmes need to be accompanied by efforts aimed at reducing child and infant mortality [22].

This study has shown that poor women compared to rich were at a higher risk of unmet need for spacing and for limiting and that women in the middle and rich categories were more protected against total unmet need compared to poor women. Rural residence increased the likelihood of the unmet need for spacing and total unmet need but played no significant role in limiting. Geographically, the multivariate analysis confirmed that the Northern region was better off in contraceptive use, compared to the Bujumbura region. This concentration of efforts in the North, which is also the most densely populated part of the country, could be a reflection that Government's concern has been primarily demographic. While the region was found a strong predictor in the univariate analysis, it lost significance once confounders were controlled.

On the other hand, visiting a health facility affords the woman the opportunity to get counseling, information, and services and has shown association with unmet need for limiting and total unmet need. In this study, women exposed to radio or TV were more protected against the unmet need for spacing, but no relationship was detected with unmet need for limiting. However, the total unmet need was influenced by exposure to TV.

\section{Limitations}

The fact that data for both the outcomes and predictors reflected the situation at one point in time prevents establishing causality relations between the dependent and independent variables, but rather a mere association. Causality supposes the anteriority of the exposure to the outcome, which is not the case in cross-sectional data.

The findings of this study have shown the importance of the man's views on fertility and contraception in the Burundi male-dominated society. It is therefore important that further researches explore male views, a dimension which was missing in this research. On the other hand, although spousal communication about FP was deemed key in future interventions, the present study did not measure it directly for lack of relevant information in the questionnaire. It was just deducted from the importance of the group of respondents reporting to ignore husband's desires. Male involvement and spousal communication constitute an area of interest for future studies on Burundi.

\section{Conclusion}

This report examined the differentials, the prevalence, and factors associated with unmet need for FP among married women in Burundi in 2010. After controlling for other respondent's characteristics, results indicate that women with unmet need for spacing were primarily younger, poor and rural, had no education, desired 6+ children, ignored their husband's fertility preferences and were not exposed to radio or TV messages. Women from the Northern Region were better protected against the unmet need for spacing.

Unmet need for limiting was associated with poor, older women aged $35+$, desiring zero to three children, having $6+$ children and, ignoring their husband's desire for children, having experienced the death of a daughter or a son and having not visited a health facility during the last 12 months before the interview.

Total unmet need was associated with poor, rural women, with no education, living with four to five or $6+$ children, ignoring their husband's fertility preferences or whose husband wants more children, who has already experienced the death of one or more sons, living in another region than the North, who has not visited a health facility during the 12 months preceding the survey and lacking access to TV messages.

Tackling the high unmet need for FP in Burundi requires multi-level interventions such as male 
involvement, promoting spousal communication, availing individual level specific services and information, increasing the use of media and designing and creating an enabling environment based on the promotion of women education, urbanization, and pro-poor policies.

\section{Abbreviations}

BDHS: Burundi Demographic and Health Survey; LMICs: Low and middleincome countries; PHC: Population and Housing Census; SRHP: Sexual and reproductive health programme; TFR: Total Fertility Rate

\section{Acknowledgments}

The authors would like to express their deepest gratitude to MEASURE DHS for granting access to the 2010 Burundi Demographic and Health Survey data.

\section{Funding}

This research was not funded.

\section{Availability of data and materials}

The data supporting the results of this study are available from the 2010 Burundi Demographic and Health Survey.

\section{Authors' contributions}

This article arose from the first author's dissertation for a master's degree at the University of Liverpool, UK, the second author acting as dissertation adviser. The present article was drafted by the first author while the second author read and edited the draft. Both authors read and approved the final manuscript.

\section{Ethics approval and consent to participate}

Not applicable

\section{Consent for publication}

Springer Nature remains neutral regarding jurisdictional claims in published maps and institutional applications.

\section{Competing interests}

The authors declare that they have no competing interests.

\section{Publisher's Note}

Springer Nature remains neutral with regard to jurisdictional claims in published maps and institutional affiliations.

\section{Author details}

${ }^{1}$ Independent Consultant, Bujumbura, Burundi. ${ }^{2}$ Department of Health Sciences, The University of Liverpool/Laureate Online Education, Liverpool, UK.

Received: 18 January 2018 Accepted: 19 April 2018

Published online: 20 June 2018

\section{References}

1. MEASURE Evaluation. Family Planning and Reproductive Health Indicators Database. Unmet need for family planning. https://www.measureevaluation. org/prh/rh_indicators/family-planning/fp/unmet-need-for-family-planning. Accessed 2 Sept 2017.

2. Bernstein $\mathrm{S}$, Edouard $\mathrm{L}$. Targeting access to reproductive health: giving contraception more prominence and using indicators to monitor progress. Reprod Health Matters. 2007:15:186-91.

3. Alkema L, Kantorova V, Menozzi C, Biddlecom A. National, regional, and global rates and trends in contraceptive prevalence and unmet need for family planning between 1990 and 2015: a systematic and comprehensive analysis. Lancet. 2013;381:1642-52.

4. Ahmed S, Li Q, Liu L, Tsui AO. Maternal deaths averted by contraceptive use: an analysis of 172 countries. Lancet. 2012;380:111-25.

5. Conde-Agudelo A, Rosas-Bermúdez A, Kafury-Goeta AC. Birth spacing and risk of adverse perinatal outcomes: a meta-analysis. JAMA. 2006;295:1809-23.
6. Imasiku EN, Odimegwu CO, Adedini SA, Ononokpono DN. Variations in unmet need for contraception in Zambia: does ethnicity play a role? J Biosoc Sci. 2014;46:294-315.

7. Dutta M, Shekhar C, Prashad L. Level, trend and correlates of mistimed and unwanted pregnancies among currently pregnant ever-married women in India. PLoS One. 2015;10:e 0144400. https://doi.org/10.1371/journal.pone.0144400.

8. Oginni A, Adebajo S, Ahonsi B. Trend and determinants of unmet need for family planning services among currently married women and sexually active unmarried women aged 15-49 in Nigeria (2003-2013). Etud Popul Afr. 2015;29:1483-500.

9. Wulifan JK, Brenner S, Jahn A, De Allegri M. A scoping review on determinants of unmet need for family planning among women of reproductive age in low and middle-income countries. BMC Women Health. 2016;16:2.

10. Adebowale SA, Palamuleni ME. Determinants of unmet need for modern contraception and reasons for non-use among married women in rural areas of Burkina Faso. APS. 2014;28:499-514.

11. Bellizzi S, Sobel HL, Obara H, Temmerman M. Underuse of modern methods of contraception: underlying causes and consequent undesired pregnancies in 35 low- and middle-income countries. Hum Reprod. 2015;30:973-86.

12. Njotang PN, Yakum MN, Ajong AB, Essi MJ, Akoh EW, Mesumbe NE, et al. Determinants of modern contraceptive practice in Yaoundé-Cameroon: a community based cross-sectional study. BMC Res Notes. 2017;10:219.

13. Ndaruhuye DM, Broekhuis A, Hooimeijer P. Demand and unmet need for means of family limitation in Rwanda. Int Perspect Sex Reprod Health. 2009; 35:122-30.

14. Ali AA, Okud A. Factors affecting unmet need for family planning in Eastern Sudan. BMC Public Health. 2013;13:102.

15. Lakew Y, Reda AA, Tamene H, Benedict S, Deribe K. Geographical variation and factors influencing modern contraceptive use among married women in Ethiopia: evidence from a national population-based survey. Reprod Health. 2013;10:52.

16. Amoako Johnson F, Madise NJ. Examining the geographical heterogeneity associated with risk of mistimed and unwanted pregnancy in Ghana. J Biosoc Sci. 2009:41(2):249-67.

17. Adhikari R, Soonthorndhada K, Prasartkul P. Correlates of unintended pregnancy among currently pregnant married women in Nepal. BMC Int Health Hum Rights. 2009;9:17.

18. Tiruneh FN, Chuang KY, Ntenda PA, Chuang YC. Factors associated with contraceptive use and intention to use contraceptives among married women in Ethiopia. Women Health. 2016;56:1-22.

19. Genet $E$, Abeje $G$, Ejigu T. Determinants of unmet need for family planning among currently married women in Dangila town administration, Awi Zone, Amhara regional state; a cross-sectional study. Reprod Health. 2015;12:42.

20. Bradley SE, Casterline JB. Understanding unmet need: history, theory, and measurement. Stud Fam Plan. 2014;45:123-50

21. Wamblebo MS, Notzi J, Kwagala B. Does couple discussion influence unmet need for family planning in Uganda? Princeton education papers. 2011. http://uaps2011.princeton.edu/papers/110381. Accessed 26 Sept 2017.

22. Beguy $\mathrm{D}$, Ezeh $\mathrm{AC}$, Mberu BU, Emina JBO. Changes in use of family planning among the urban poor: evidence from the Nairobi slums. Pop Dev Rev. 2017:43:216-34

\section{Ready to submit your research? Choose BMC and benefit from}

- fast, convenient online submission

- thorough peer review by experienced researchers in your field

- rapid publication on acceptance

- support for research data, including large and complex data types

- gold Open Access which fosters wider collaboration and increased citations

- maximum visibility for your research: over $100 \mathrm{M}$ website views per year

At BMC, research is always in progress.

Learn more biomedcentral.com/submissions 